\title{
Vascular adhesion protein-1 and renalase in regard to diabetes in hemodialysis patients
}

\author{
Ewa Koc-Zorawska, Jolanta Malyszko, Edyta Zbroch, Jacek Malyszko, Michal Mysliwiec
}

Department of Nephrology and Transplantology, Medical University, Bialystok, Poland

Submitted: 1 July 2012

Accepted: 14 August 2012

Arch Med Sci 2012; 8, 6: 1048-1052

DOI: $10.5114 /$ aoms.2012.32413

Copyright @ 2012 Termedia \& Banach

\section{Abstract}

Introduction: Vascular adhesion protein-1 (VAP-1) is a copper-containing semicarbazide-sensitive amine oxidase (SSAO) secreted by vascular smooth muscle cells, adipocytes, and endothelial cells with functional monoamine oxidase activity. Renalase, with possible monoamine oxidase activity, which breaks down catecholamines like SSAO, is also expressed in the endothelium as well as in the kidney. The aim of the study was to assess VAP-1 level and its correlation with renalase level in 60 hemodialyzed (HD) patients.

Material and methods: Complete blood count, urea, serum lipids, fasting glucose and creatinine were studied by the standard laboratory method in the hospital central laboratory. We assessed VAP-1 and renalase with commercially available assays.

Results: The mean level of VAP-1 as well as renalase was significantly higher in HD patients when compared to the control group $(291.01 \pm 94.91 \mathrm{ng} / \mathrm{ml}$ vs. 158.34 $\pm 56.89 \mathrm{ng} / \mathrm{ml}, p<0.01 ; 27.53 \pm 9.394 .91 \mu \mathrm{g} / \mathrm{ml}$ vs. $4.00 \pm 1.37 \mu \mathrm{g} / \mathrm{ml}, p<0.001$, respectively). In hemodialysis patients VAP-1 correlated with presence of diabetes $(r=0.27, p<0.05)$, presence of hypertension $(r=0.32, p<0.05)$, use of calcium channel blockers $(r=0.30, p<0.05)$, use of $\beta$-blockers $(r=0.25$, $p<0.05)$, ejection fraction $(r=-0.38, p<0.01)$, systolic blood pressure before $(r=0.52, p<0.001)$ and after hemodialysis $(r=0.30, p<0.01)$, and weight gain $(r=0.41, p<0.01)$. Renalase was not significantly different in diabetic and nondiabetic patients or between hypertensive and normotensive patients. In multiple regression analysis VAP-1 was predicted $77 \%$ by serum ejection fraction and fibrinogen.

Conclusions: Vascular adhesion protein-1, elevated in patients on hemodialysis, was predominantly dependent on blood pressure and diabetes, both factors associated with endothelial damage and promoting cardiovascular complications. Renalase appeared to be unrelated to VAP, at least in the HD population.

Key words: vascular adhesion protein-1, renalase, hemodialysis, diabetes.

\section{Introduction}

Vascular adhesion protein-1 (VAP-1) is a dual-function protein [1]. Endothelial VAP-1 can act as an adhesion molecule [2] and is involved in leukocyte rolling, adhesion, and transmigration, which are central steps during leukocyte extravasation to sites of inflammation, such as atherosclerotic lesions [3]. On the other hand, VAP-1 is a copper-containing semicarbazide-sensitive amine oxidase (SSAO) secreted by vascular smooth muscle cells, adipocytes, and endothelial cells, with functional monoamine oxidase activity [2]. It may function as a scavenger enzyme to assist MAO,

\author{
Corresponding author: \\ Prof. Jolanta Malyszko \\ $\mathrm{MD}, \mathrm{PhD}$ \\ Department of Nephrology \\ and Transplantology \\ Medical University \\ 14 Zurawia St \\ 15-540 Bialystok, Poland \\ Phone: +48 857409464 \\ E-mail: jolmal@poczta.onet.pl
}


but it is insensitive to MAO inhibitors. High activity levels of this enzyme are associated with diabetes, atherosclerosis, or stroke [4-6], thus meaning that studies concerning SSAO, as a therapeutic target, are becoming more frequent. Therefore, as an adhesion molecule and an enzyme, SSAO/ VAP-1 can participate in the development of atherosclerosis. It has been shown that serum VAP-1 is elevated in acute and chronic hyperglycemia and in patients with diabetes [7]. In addition, it has also been noted that the change in serum VAP-1 after glucose challenge was correlated with systemic oxidative stress, advanced glycation end-products (AGEs), and carotid intima-medial thickness, which is an index for atherosclerosis [8]. It has been reported that subjects with chronic kidney disease have higher serum VAP-1 [9], suggesting a possibility that serum VAP-1 may be excreted by the kidneys. Endothelial dysfunction is highly prevalent in cardiovascular disease, diabetes and chronic kidney disease [10-12]. Cardioprotection is the most powerful nephroprotection [13]. Recently, Li et al. [14] have indicated that serum VAP-1 may be a good predictor of cardiovascular mortality in type 2 diabetes. Taking all these data into consideration, the aim of the study was to assess VAP-1 level and its relation to diabetes and renalase, a novel protein probably involved in blood pressure regulation and possessing monoamine oxidase activity, in prevalent hemodialysis patients.

\section{Material and methods}

The studies were performed on 60 prevalent haemodialysis (HD) patients (mean age: 62.19 \pm 15.68 years). The mean duration of HD was 50 months. All patients were informed about the aim of the study and gave their informed consent. The study was approved by the Medical University Ethic Committee. Inclusion criteria were: a stable clinical state, no thrombosis or inflammation (C-reactive protein within normal range, i.e. below $6 \mathrm{mg} / \mathrm{l}$ using a semiquantitative method), absence of acute cardiovascular complications (including uncontrolled hypertension, acute coronary syndrome, acute heart failure). Patients with renal graft failure and/or on immunosuppressive therapy were excluded. The body mass index (BMI) was calculated according to the dry weight. The presence of residual renal function was based on the 24-hour urine collection. The presence of residual renal function was defined as the 24-hour urine collection above $100 \mathrm{ml}$. The blood pressure (BP) was measured in the HD group before and after a hemodialysis session in the sitting position using an automatic manometer. The arithmetic average of three measurements taken in three consecutive dialysis sessions was used for the analysis; the same rule applied for the weight gain between dialysis sessions. Well-controlled blood pressure level according to K/DOQI guidelines [15] was defined as lower than $140 / 90 \mathrm{~mm} \mathrm{Hg}$ in HD patients before a hemodialysis session and lower than $130 / 80 \mathrm{~mm} \mathrm{Hg}$ after that. All hypotensive drugs were collected from the individual prescription cards. Kt/v was assessed according to the standard method. The blood for the estimation of the renalase and VAP-1 concentration was taken once before the hemodialysis session in the middle of three dialysis sessions (when also BP and weight were assessed). The enzyme-linked immunosorbent assay (ELISA) kit made by Uscn Life Science Inc. China, using a monoclonal antibody specific to renalase, was used to assess renalase level. Vascular adhesion protein-1 was assessed using kits from BioVendor, Modrice, Czech Republic. Healthy volunteers $(n=16)$ were included in the study to obtain normal ranges for VAP-1 and renalase.

\section{Statistical analysis}

The data obtained were analyzed using Statistica 9.0 computer software (Tulsa, OK, USA). The examination of the distribution normality of variables was done using the Shapiro-Wilk W test, and Student's $t$-test and Mann-Whitney $U$ test were used for comparison of the two groups. The data were also logarithmically transformed to achieve normal distribution, whenever possible. Measurements normally distributed are reported as mean $\pm S D$, while non-normally distributed data are expressed as median and minimal-maximal value. Spearman or Pearson correlations were evaluated, as appropriate, with $p<0.05$ considered statistically significant. Multiple regression analysis was used to determine independent factors affecting the dependent variable. Factors showing a linear correlation with VAP-1 $(p<0.1)$ were included in the analysis.

\section{Results}

The clinical and biochemical data are presented in Table I. The mean level of VAP-1 as well as renalase was significantly higher in HD patients when compared to the control group $(291.01 \pm 94.91 \mathrm{ng} / \mathrm{ml}$ vs. $158.34 \pm 56.89 \mathrm{ng} / \mathrm{ml}, p<0.01 ; 27.53 \pm 9.394 .91$ $\mu \mathrm{g} / \mathrm{ml}$ vs. $4.00 \pm 1.37 \mu \mathrm{g} / \mathrm{ml}, p<0.001)$. Diabetic patients had higher serum VAP-1 than non-diabetics, whereas serum renalase did not differ significantly (Table I).

Patients with blood pressure over 140/90 mm Hg $(n=24)$ had higher VAP-1 levels when compared to patients with lower blood pressure values (322.84 $\pm 101.28 \mathrm{ng} / \mathrm{ml}$ vs. $274.40 \pm 76.58 \mathrm{ng} / \mathrm{ml}, p<0.05)$, whereas serum renalase did not differ significantly $(26.98 \pm 6.98 \mathrm{ng} / \mathrm{ml}$ vs. $30.11 \pm 8.34 \mathrm{ng} / \mathrm{ml}$, NS $)$. Patients with hemoglobin over $10 \mathrm{~g} / \mathrm{dl}(n=50)$ had 
Table I. Clinical and biochemical characteristics of diabetic and non-diabetic hemodialysis patients

\begin{tabular}{|c|c|c|}
\hline Parameter & HD DM $(+)(n=19)$ & $\operatorname{HD~DM~}(-)(n=41)$ \\
\hline Age [years] & $69.33 \pm 10.94$ & $57.60 \pm 16.66^{\star \star \star}$ \\
\hline Dialysis vintage [months] & $35.35 \pm 28.95$ & $59.56 \pm 62.71$ \\
\hline Hemoglobin $[\mathrm{g} / \mathrm{dl}]$ & $10.98 \pm 1.48$ & $11.03 \pm 1.54$ \\
\hline Erythrocyte count $\left[\times 10^{12} / \mu \mathrm{l}\right]$ & $3.60 \pm 0.57$ & $3.64 \pm 0.48$ \\
\hline $\mathrm{MCV}[\mathrm{fmol}]$ & $95.71 \pm 7.34$ & $94.19 \pm 6.39$ \\
\hline Leukocyte count $\left[\times 10^{3} / \mu l\right]$ & $6.64 \pm 1.77$ & $6.27 \pm 1.99$ \\
\hline Platelet count $\left[\times 10^{6} / \mu \mathrm{ll}\right]$ & $210.48 \pm 46.41$ & $173.36 \pm 66.74^{*}$ \\
\hline Urea pre HD [mg/dl] & $112.57 \pm 38.28$ & $130.07 \pm 41.90$ \\
\hline $\mathrm{Kt} / \mathrm{V}$ & $1.23 \pm 0.22$ & $1.38 \pm 0.21^{*}$ \\
\hline Residual renal function [ml] & $457.14 \pm 494.79$ & $264.17 \pm 408.23^{*}$ \\
\hline TSAT [\%] & $33.30 \pm 13.20$ & $31.33 \pm 13.61$ \\
\hline Ferritin [ng/ml] & $341.65 \pm 143.04$ & $491.69 \pm 421.80$ \\
\hline Cholesterol [mg/dl] & $172.90 \pm 34.36$ & $170.56 \pm 37.84$ \\
\hline Triglycerides [mg/dl] & $144.30 \pm 100.56$ & $131.27 \pm 48.66$ \\
\hline Fibrinogen $[\mathrm{mg} / \mathrm{l}]$ & $406.39 \pm 86.99$ & $381.35 \pm 110.40$ \\
\hline Dry weight [kg] & $83.50 \pm 26.54$ & $69.27 \pm 16.50^{\star \star}$ \\
\hline Weight gain between HD [kg] & $2.88 \pm 1.86$ & $1.97 \pm 1.23^{*}$ \\
\hline $\mathrm{BMI}\left[\mathrm{kg} / \mathrm{m}^{2}\right]$ & $29.87 \pm 4.29$ & $25.13 \pm 5.08^{\star}$ \\
\hline Systolic blood pressure pre $\mathrm{HD}$ [mm Hg] & $138.57 \pm 22.32$ & $136.58 \pm 22.28$ \\
\hline Diastolic blood pressure pre $\mathrm{HD}$ [mm Hg] & $68.70 \pm 89.51$ & $79.50 \pm 13.29^{\star *}$ \\
\hline Systolic blood pressure post HD [mm Hg] & $123.71 \pm 34.61$ & $125.19 \pm 26.14$ \\
\hline Diastolic blood pressure post $\mathrm{HD}[\mathrm{mm} \mathrm{Hg}]$ & $66.12 \pm 8.86$ & $71.85 \pm 12.97$ \\
\hline ACE inhibitors [\%] & 48 & 42 \\
\hline ARB [\%] & 10 & 0 \\
\hline$\beta$-Blockers [\%] & 71 & 58 \\
\hline Calcium channel blockers [\%] & 67 & 61 \\
\hline Diuretics [\%] & 24 & 22 \\
\hline Renalase $[\mu \mathrm{g} / \mathrm{ml}]$ & $25.85 \pm 9.17$ & $28.76 \pm 6.26$ \\
\hline VAP-1 [ng/ml] & $322.69 \pm 106.74$ & $278.95 \pm 76.69^{\star}$ \\
\hline
\end{tabular}

Data given are means $\pm S D,{ }^{*} p<0.05,{ }^{* *} p<0.01,{ }^{* \star *} p<0.001$

lower VAP-1 than patients with anemia defined as hemoglobin less than $10 \mathrm{~g} / \mathrm{dl}(241.22 \pm 55.32 \mathrm{ng} / \mathrm{ml}$ vs. $302.84 \pm 96.06 \mathrm{ng} / \mathrm{ml}, p<0.05)$. No difference in VAP-1 was found between patients with and without coronary artery disease or with and without residual renal function. Males $(n=26)$ had higher VAP-1 levels than females $(322.56 \pm 102.41 \mathrm{ng} / \mathrm{ml}$ vs. $271.42 \pm 78.45 \mathrm{ng} / \mathrm{ml}, p<0.05)$. Patients treated with $\beta$-blockers had higher VAP-1 than non-treated $(309.47 \pm 103.39 \mathrm{ng} / \mathrm{ml}$ vs. $261.31 \pm 71.88 \mathrm{ng} / \mathrm{ml}$, $p<0.05)$, and those treated with calcium channel blockers had higher VAP-1 than non-treated (312.99 $\pm 101.28 \mathrm{ng} / \mathrm{ml}$ vs. $255.66 \pm 72.71 \mathrm{ng} / \mathrm{ml}, p<0.05$ ).

In univariate analysis, VAP-1 correlated with the presence of diabetes $(r=0.27, p<0.05)$, the pres- ence of poorly controlled blood pressure (values above $140 / 90 \mathrm{~mm} \mathrm{Hg})(r=0.32, p<0.05)$, use of calcium channel blockers $(r=0.30, p<0.05)$, use of $\beta$-blockers $(r=0.25, p<0.05)$, ejection fraction $(r=-0.38, p<0.01)$, systolic blood pressure before $(r=0.52, p<0.001)$ and after hemodialysis $(r=0.30$, $p<0.01)$, weight gain $(r=0.41, p<0.01)$, and mean cell volume (MCV) $(r=-0.29, p<0.05)$. Vascular adhesion protein-1 tended to correlate with fibrinogen $(r=0.22, p=0.09)$ and white blood cell count $(r=-0.24, p=0.06)$. In multiple regression analysis VAP-1 was predicted $77 \%$ by serum ejection fraction ( $\beta=0.66, p=0.000668)$, and fibrinogen $(\beta=0.59, p=0.007) ; F=3.49$, SE $=53.23$ and $p<0.001$. 


\section{Discussion}

We found that VAP-1 was significantly higher in hemodialysis patients when compared to the healthy volunteers. Moreover, in our study we showed that VAP-1 in hemodialysis patients was related to the ejection fraction. In addition, VAP-1 was significantly higher in diabetic and hypertensive patients when compared to their non-diabetic and normotensive counterparts.

A few years ago Xu et al. [16] described the novel putative substance named renalase, and its possible role in hypertension and cardiovascular complications. Xu et al. [16] originally reported that renalase had weak monoamine oxidase activity (it was patented by Gesir GV, \#US patent 7,700,095 B2: Detection, Isolation and Uses of Renalase (Monoamine Oxidase $\mathrm{C}$ )). However, other researchers could not confirm that renalase was a monoamine oxidase or even an oxidase at all, as shown in a review by Malyszko et al. [17]. On the other hand, serum VAP-1 originated from many tissues, with similarity to renalase distribution. However, in our study we could not prove, even in univariate analysis, correlations between VAP-1 and renalase. Renalase is supposed to exhibit monoamine oxidase activity [16]. In our previous study, we reported the correlations between renalase and endothelium injury markers; however, the renalase levels were predicted by kidney function [18]. It might be due to the fact that together with a decline in kidney function, endothelial damage was increased. In kidney allograft recipients, VAP-1 was related to renalase in univariate analysis, but in multivariate analysis it was predicted by kidney function and a marker of endothelial cell injury, CD146 [19]. Then we looked at possible relations between VAP-1 and cardiovascular complications. We found that VAP-1 did not differ between patients with and without coronary artery disease. As reviewed by Aronow [20], diabetes and cardiovascular disease, predominant comorbidities in our population, should be treated with optimal medical management and additionally all modifiable risk factors should be treated. In our study we found that in patients with elevated blood pressure, VAP-1 levels were also increased, suggesting more pronounced endothelial damage. In this study in the HD population we did not find a correlation between VAP-1 and renalase. We might speculate that renalase was accumulated in the HD population and due to profound endothelial cell damage and many comorbidities, such as diabetes, hypertension, dyslipidemia, heart failure and coronary artery disease, the relations are so complicated and not precisely known.

Li et al. [9] suggested a possibility that serum VAP-1 might be excreted by the kidneys; thus we
Table II. Cardiac parameters of diabetic and non-diabetic hemodialysis patients

\begin{tabular}{|lcc|}
\hline Parameter & HD DM (+) & HD DM (-) \\
\hline NYHA class & $2.16 \pm 1.02$ & $1.81 \pm 0.76^{*}$ \\
\hline EF [\%] & $55.9 \pm 7.9$ & $55.1 \pm 9.5$ \\
\hline LVIDd [mm] & $50.2 \pm 4.8$ & $49.2 \pm 6.6$ \\
\hline LVISd [mm] & $34.9 \pm 3.0$ & $33.4 \pm 4.6$ \\
\hline RV [mm] & $30.7 \pm 3.7$ & $29.8 \pm 4.1$ \\
\hline LA [mm] & $43.2 \pm 4.9$ & $41.0 \pm 5.6$ \\
\hline RA [mm] & $41.2 \pm 6.1$ & $47.6 \pm 10.9$ \\
\hline IVS [mm] & $12.8 \pm 1.4$ & $12.5 \pm 2.4$ \\
\hline
\end{tabular}

Data are given as mean $\pm S D,{ }^{*} p<0.05$, proximal vs. distal AVF; $E F$ - ejection fraction, LVIDd - left ventricular internal end-diastolic dimension, LVISd - left ventricular internal end-systolic dimension, $R V$ - right ventricle, $L A$ - left atrium, $R A$ - right atrium, IVS - inter-ventricular septum diastole dimension

investigated whether VAP-1 was dependent on kidney function. In their study serum VAP-1 levels were positively associated with the urinary albumin-tocreatinine ratio and inversely correlated with estimated glomerular filtration rate. Patients with chronic kidney disease (CKD) stage 2 and 3 had significantly higher levels of serum VAP-1 than those without CKD. A high serum VAP-1 level was associated with the presence of CKD after adjustment for age, sex, and smoking. However, we found no difference in VAP-1 levels in patients with and without residual renal function. In addition, in our population, diabetic $(n=6)$ and hypertensive $(n=30)$ hemodialysis patients had significantly higher VAP-1 than non-diabetic and normotensive subjects. Li et al. [7] reported previously that serum VAP-1 was higher in subjects with acute and chronic hyperglycemia and with diabetes. Moreover, they also showed for the first time that serum VAP-1 could independently predict 10-year all-cause mortality and cardiovascular mortality in subjects with type 2 diabetes [13]. In addition, they also noted that the change in serum VAP-1 after glucose challenge correlated with systemic oxidative stress, AGEs, and carotid intima-media thickness, which was an index for atherosclerosis [8]. In our study, VAP-1 did not differ between patients with and without coronary artery disease, but was predicted by ejection fraction.

Endothelial cell injury is a common finding in dialysis patients, as we discussed previously [11]. Endothelial VAP-1 can participate in inflammation by binding granulocytes, lymphocytes, and monocytes, with the aid of SSAO activity [2]. Fibrinogen is an acute phase reactant and is also associated with progression of atherosclerosis in patients with chronic kidney disease [21]. Experiments with cell cultures suggested that, at least in part, serum VAP-1 came from the shedding of VAP-1 from the surface of adipocytes through the effect of a metal- 
loproteinase $[22,23]$, which could be affected by hyperglycemia [24]. However, the way in which serum VAP-1 was cleared from the circulation remained unknown. We are fully aware of the limitations of the study, being single center and crosssectional. It was still a matter of debate whether the commercial assay used for renalase estimation was validated. We did not study MAO activity and its correlation with VAP-1 and renalase or flowmediated dilation as a marker of endothelial dysfunction. Data on VAP-1 as well as renalase in $\mathrm{CKD} / \mathrm{HD}$ are also very limited and sometimes conflicting [25].

In conclusion, VAP-1, elevated in patients on renal replacement therapy, is predominantly dependent on blood pressure and diabetes, both factors associated with endothelial damage and promoting cardiovascular complications. Li et al. [13] suggested even a potential use of VAP-1/SSAO inhibitors or antibodies, currently being tested for their ability to modulate autoimmune disturbances and to treat or prevent cardiovascular diseases, particularly in type 2 diabetes.

\section{Acknowledgments}

The work was supported in part by an unrestricted educational Baxter grant from the Polish Society of Nephrology.

\section{References}

1. Salmi M, Jalkanen S. A 90-kilodalton endothelial cell molecule mediating lymphocyte binding in humans. Science 1992; 257: 1407-9.

2. Merinen M, Irjala H, Salmi M, Jaakkola I, Hänninen A, Jalkanen S. Vascular adhesion protein-1 is involved in both acute and chronic inflammation in the mouse. Am J Pathol 2005; 166: 793-800.

3. Mazzone T, Chait A, Plutzky J. Cardiovascular disease risk in type 2 diabetes mellitus: insights from mechanistic studies. Lancet 2008; 371: 1800-9.

4. Noda K, Nakao S, Zandi S, et al. Vascular adhesion protein-1 regulates leukocyte transmigration rate in the retina during diabetes. Exp Eye Res 2009; 89: 774-81.

5. Stolen CM, Madanat R, Marti L, et al. Semicarbazide sensitive amine oxidase overexpression has dual consequences: insulin mimicry and diabetes-like complications. FASEB J 2004; 18: 702-4.

6. Salmi M, Stolen C, Jousilahti P, et al. Insulin-regulated increase of soluble vascular adhesion protein-1 in diabetes. Am J Pathol 2002; 161: 2255-62.

7. Li HY, Wei JN, Lin MS, et al. Serum vascular adhesion protein-1 is increased in acute and chronic hyperglycemia. Clin Chim Acta 2009; 404: 149-53.

8. Li HY, Lin MS, Wei JN, et al. Change of serum vascular adhesion protein-1 after glucose loading correlates to carotid intima-medial thickness in non-diabetic subjects. Clin Chim Acta 2009; 403: 97-101.

9. Lin MS, Li HY, Wei JN, et al. Serum vascular adhesion protein-1 is higher in subjects with early stages of chronic kidney disease. Clin Biochem 2008; 41: 1362-7.

10. Malyszko J, Malyszko JS, Pawlak K, et al. The coagulolytic system and endothelial function in cyclosporine-treated kidney allograft recipients. Transplantation 1996; 62: 828-30.

11. Malyszko J. Mechanism of endothelial dysfunction in chronic kidney disease. Clin Chim Acta 2010; 411: 1412-20.

12. Barylski M, Małyszko J, Rysz J, Myśliwiec M, Banach M. Lipids, blood pressure, kidney - what was new in 2011? Arch Med Sci 2011; 7: 1055-66.

13. Li HY, Jiang YD, Chang TJ, et al. Serum vascular adhesion protein-1 predicts 10-year cardiovascular and cancer mortality in individuals with type 2 diabetes. Diabetes 2011; 60: 993-9.

14. Couser WG, Riella MC. World Kidney Day 2011 - Protect your kidneys, save your heart. Arch Med Sci 2011; 7: 1-4.

15. K/DOQI Clinical Practice Guidelines for Cardiovascular Disease in Dialysis Patients. Am J Kidney Dis 2005; 45(Suppl 3): S49.

16. Xu J, Li G, Wang P, et al. Renalase is a novel, soluble monoamine oxidase that regulates cardiac function and blood pressure. J Clin Invest 2005; 115: 1275-80.

17. Malyszko J, Malyszko JS, Mikhailidis DP, Rysz J, Zorawski M, Banach M. Hypertension and kidney disease: is renalase a new player or an innocent bystander? J Hypertens 2012; 30: 457-62.

18. Zbroch E, Małyszko J, Małyszko J, et al. Renalase, kidney function and markers of endothelial dysfunction in renal transplant recipients. Pol Arch Med Wewn 2012; 122: 174-9.

19. Malyszko J, Koc-Zorawska E, Malyszko JS, Mysliwiec M. VAP-1, a nover molecule linked to endothelial damage and kidney function in kidney allograft recipients. The Transplant Congress, Berlin 15-19.07, 2012 abstract PO24.088.

20. Aronow WS. Editorial on management of diabetes mellitus with coronary artery disease. Arch Med Sci 2011; 7: 928-30.

21. Hiramoto JS, Katz R, Peralta CA, et al. Inflammation and coagulation markers and kidney function decline: The Multi-Ethnic Study of Atherosclerosis (MESA). Am J Kidney Dis 2012; 60: 225-32.

22. García-Vicente $\mathrm{S}$, Abella A, Viguerie $\mathrm{N}$, et al. The release of soluble VAP-1/SSAO by 3T3-L1 adipocytes is stimulated by isoproterenol and low concentrations of TNFalpha. J Physiol Biochem 2005; 61: 395-401.

23. Abella A, García-Vicente S, Viguerie N, et al. Adipocytes release a soluble form of VAP-1/SSAO by a metalloprotease-dependent process and in a regulated manner. Diabetologia 2004; 47: 429-38.

24. Lewandowski KC, Banach E, Bieńkiewicz M, Lewiński A. Matrix metalloproteinases in type 2 diabetes and nondiabetic controls: effects of short-term and chronic hyperglycaemia. Arch Med Sci 2011; 7: 294-303.

25. Malyszko J, Malyszko JS, Rysz J, et al. Renalase, hypertension, and kidney: the discussion continues. Angiology 2012 Sep 11 [Epub ahead of print]. 